\title{
Autoamputation of a large pedunculated colon polyp
}

A 49-year-old man was referred for colonoscopy after a positive fecal occult blood test. Laboratory tests and physical examination were unremarkable but colonoscopy revealed a large pedunculated polyp in the sigmoid colon ( $\bullet$ Fig. 1). Owing to inadequate bowel cleansing, polypectomy was not carried out.

On repeat colonoscopy 120 days later, bowel cleansing was excellent. The examination was performed by an expert endoscopist, under good vision with adequate colonic distension and no blind angulations. However, despite every effort, the endoscopist was unable to find the polyp.A second expert endoscopist repeated the examination in the same session, and although he reached the cecum twice, he also could not detect the polyp.Interestingly, both endoscopists observed a prolapse of the normal mucosa, with a scar on the edge, in the site where the polyp had been previously seen ( Fig.2). On close inspection, no adenomatous tissue was visible. We hypothesized that polyp autoamputation had occurred, with the prolapsed mucosa being the remnant of the stalk of the amputated polyp.Indeed, the patient reported having passed some bright red material and clots per rectum a few weeks before, with no significant consequences. To our knowledge, only three cases of colonic polyp autoamputation have been reported [1,2]. Autoamputation has also been described in the stomach [3] and in the duodenum [4], mainly with the pedunculated types of polyp, which are subject to higher mechanical traction and torsion of the stalk. The present case is the first with documented endoscopic images both before and after the event. Autoamputation can be asymptomatic or accompanied by abdominal pain and bleeding, eventually leading to hospitalization [4]. No fatalities have been reported. Intrinsic limitations of colonoscopy are usually the first reason mentioned for missed polyps [5]. Nevertheless, gastroenterologists should consider the possibility of autoamputation in

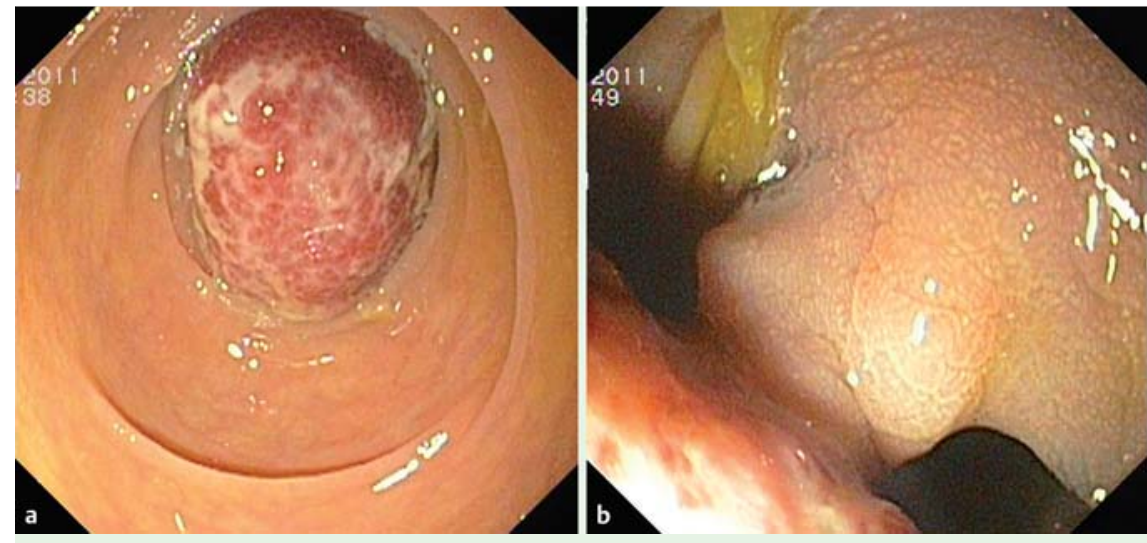

Fig. 1 The head of the polyp seen at the first colonoscopy in a 49-year-old man with a positive fecal occult blood test. a The polyp is occupying almost the entire lumen of the sigmoid colon. $\mathbf{b}$ View of the stalk of the polyp.

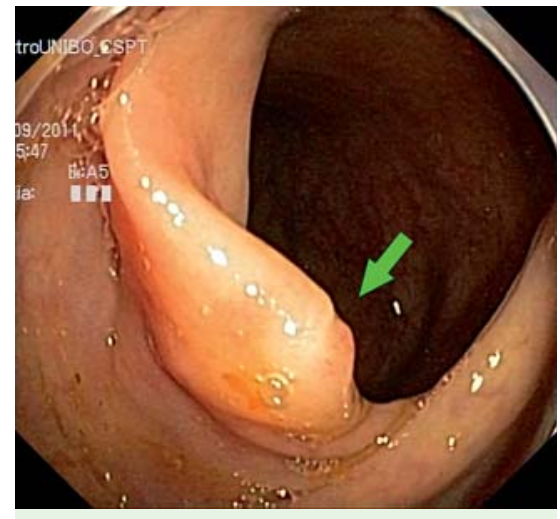

Fig. 2 At follow-up colonoscopy, only a small mucosal prolapse was seen at the site where the polyp had previously been detected (arrow).

the case of pedunculated polyps that are not found in subsequent colonoscopies.

\section{Endoscopy_UCTN_Code_CCL_1AD_2AB}

\section{Competing interests: None}

\section{P. Fusaroli, V. Feletti, G. Caletti}

Department of Clinical Medicine, GI Unit, University of Bologna/Hospital of Imola, Bologna, Italy

\section{References}

1 Paul RE Jr, Gherardi GJ, Miller HH. Autoamputation of benign and malignant colonic polyps: report of two cases. Dis Colon Rectum 1974; 17: 331 - 335

2 Kaneki T, Kawashima A, Tsushima $K$ et al. Submucosal tumor-like elevated lesion after autoamputation of a colonic polyp. Gastrointest Endosc 2002; 55: 444 - 446

3 Nakajima T, Kamano T, Watanabe $K$ et al. A gastric hyperplastic polyp observed endoscopically before and after autoamputation. Endoscopy 2003; 35: 1069-1071

4 Iacopini $G$, De Cesare A, Iacopini $F$ et al. A "vanishing" cause of upper gastrointestinal haemorrhage. Pathogenetic hypothesis of autoamputation. Gut 2008; 57: 1503, 1591

5 van Rijn JC, Reitsma JB, Stoker J et al. Polyp miss rate determined by tandem colonoscopy: a systematic review. Am J Gastroenterol 2006; 101: $343-350$

Bibliography

Dol http://dx.doi.org/

10.1055/s-0031-1291757

Endoscopy 2012; 44: E127

(c) Georg Thieme Verlag KG

Stuttgart · New York

ISSN 0013-726X

\section{Corresponding author}

Dr. P. Fusaroli

Ospedale di Castel S. Pietro Terme

Viale Oriani 1

40024 Castel S. Pietro Terme

Fax: +39-051-6955206

pietro.fusaroli@unibo.it 